\title{
Erratum to: Diagnosis of neglected tropical diseases among patients with persistent digestive disorders (diarrhoea and/or abdominal pain $\geq 14$ days): a multi-country, prospective, non-experimental case-control study
}

\author{
Katja Polman ${ }^{1 *+}$, Sören L. Becker ${ }^{2,3,4,5+}$, Emilie Alirol ${ }^{6}$, Nisha K. Bhatta ${ }^{7}$, Narayan R. Bhattarai ${ }^{8}$, Emmanuel Bottieau ${ }^{9}$, \\ Martin W. Bratschi ${ }^{2,3}$, Sakib Burza ${ }^{10}$, Jean T. Coulibaly ${ }^{11,12,2,3}$, Mama N. Doumbia ${ }^{13}$, Ninon S. Horié ${ }^{6}$, Jan Jacobs ${ }^{7}$, \\ Basudha Khanal ${ }^{8}$, Aly Landouré ${ }^{13}$, Yodi Mahendradhata ${ }^{14}$, Filip Meheus ${ }^{15}$, Pascal Mertens ${ }^{16}$, Fransiska Meyanti $^{14}$, \\ Elsa H. Murhandarwati ${ }^{14}$, Eliézer K. N'Goran ${ }^{11,12}$, Rosanna W. Peeling ${ }^{10}$, Raffaella Ravinetto ${ }^{17,8}$, Suman Rijal ${ }^{18}$, \\ Moussa Sacko ${ }^{13}$, Rénion Saye ${ }^{13}$, Pierre H. H. Schneeberger ${ }^{19,20,2,3}$, Céline Schurmans ${ }^{9}$, Kigbafori D. Silué ${ }^{11,12}$, \\ Jarir A. Thobari ${ }^{14}$, Mamadou S. Traoré ${ }^{13}$, Lisette van Lieshout ${ }^{21}$, Harry van Loen ${ }^{9}$, Kristien Verdonck ${ }^{22}$, \\ Lutz von Müller ${ }^{4,5}$, Cédric P. Yansouni ${ }^{23}$, Joel A. Yao ${ }^{11,12}$, Patrick K. Yao ${ }^{11}$, Peiling Yap ${ }^{2,3}$, Marleen Boelaert ${ }^{22}$, \\ François Chappuis ${ }^{6}$ and Jürg Utzinger ${ }^{2,3}$
}

Unfortunately the original article [1] contained a typo in the title. Instead of "Diagnosis of neglected tropical diseases among patients with persistent digestive disorders (diarrhoea and/or abdominal pain $\geq 14$ days): a multi-country, prospective, non-experimental casecontrol study" the articles was accidentally called "Diagnosis of neglected tropical diseases among patients with persistent digestive disorders (diarrhoea and/or abdominal pain $\geq 14$ days): Pierrea multicountry, prospective, non-experimental case-control study". This has now been updated in the original article and corrected with this erratum.

\section{Author details}

'Department of Biomedical Sciences, Institute of Tropical Medicine, Antwerp, Belgium. ${ }^{2}$ Department of Epidemiology and Public Health, Swiss Tropical and Public Health Institute, Basel, Switzerland. ${ }^{3}$ University of Basel, Basel, Switzerland. ${ }^{4}$ Institute of Medical Microbiology and Hygiene, Saarland University, Homburg, Germany. ${ }^{5}$ nstitute of Medical Microbiology and Hygiene, Saarland University, Saar, Germany. ${ }^{6}$ Division of Tropical and Humanitarian Medicine, Geneva University Hospitals, Geneva, Switzerland. ${ }^{7}$ Department of Paediatrics and Adolescent Medicine, B P Koirala Institute of Health Sciences, Dharan, Nepal. ${ }^{8}$ Department of Microbiology, B P Koirala Institute of Health Sciences, Dharan, Nepal. ${ }^{9}$ Department of Clinical Sciences,
Institute of Tropical Medicine, Antwerp, Belgium. ${ }^{10}$ London School of Hygiene and Tropical Medicine, London, UK. ${ }^{11}$ Unité de Formation et de Recherche Biosciences, Université Félix Houphouët-Boigny, Abidjan, Côte d'Ivoire. ${ }^{12}$ Département Environnement et Santé, Centre Suisse de Recherches Scientifiques en Côte d'Ivoire, Abidjan, Côte d'Ivoire. ${ }^{13}$ Institut National de Recherche en Santé Publique, Bamako, Mali. ${ }^{14}$ Centre for Tropical Medicine, Faculty of Medicine, Gadjah Mada University, Yogyakarta, Indonesia. ${ }^{15}$ University of Cape Town, Cape Town, South Africa. ${ }^{16}$ Coris BioConcept, Gembloux, Belgium. ${ }^{17}$ Department of Pharmaceutical and Pharmacological Sciences, KU Leuven, Leuven, Belgium. ${ }^{18}$ Department of Internal Medicine, B P Koirala Institute of Health Sciences, Dharan, Nepal. ${ }^{19}$ Department of Epidemiology and Molecular Diagnostics, Agroscope Changins-Wädenswil ACW, Wädenswil, Switzerland. ${ }^{20}$ Department of Virology, Spiez Laboratory, Federal Office for Civil Protection, Spiez, Switzerland. ${ }^{21}$ Department of Parasitology, Leiden University Medical Center Leiden, The Netherlands. ${ }^{22}$ Department of Public Health, Institute of Tropical Medicine, Antwerp, Belgium. ${ }^{23}$ Divisions of Infectious Diseases and Medical Microbiology, J.D. MacLean Centre for Tropical Diseases, McGill University Health Centre, Montreal, Canada.

Received: 30 September 2015 Accepted: 30 September 2015 Published online: 04 November 2015

Reference

1. Polman $\mathrm{K}$ et al. Diagnosis of neglected tropical diseases among patients with persistent digestive disorders (diarrhoea and/or abdominal pain $\geq 14$ days): a multi-country, prospective, non-experimental case-control study. BMC Infect Dis. 2015:15:338

\footnotetext{
* Correspondence: kpolman@itg.be

${ }^{\dagger}$ Equal contributors

'Department of Biomedical Sciences, Institute of Tropical Medicine, Antwerp, Belgium

Full list of author information is available at the end of the article
} 